\title{
A Nuanced Account: Why Do Individuals Engage in Sexting?
}

\author{
Joris Van Ouytsel, Michel Walrave, and Koen Ponnet
}

\begin{abstract}
Based on a review of both quantitative and qualitative studies, this chapter aims to explore individuals' motives for engaging in sexting. The chapter outlines adolescents' and adults' various reasons for engaging in sexting, both inside and outside the context of a romantic relationship. These reasons include flirting with a date and sustaining intimacy within an already established romantic relationship. The chapter also focuses on the pressure that often accompanies sexting. Finally, the chapter discusses the potentially positive effects of exchanging sexually explicit pictures.
\end{abstract}

Keywords Sexting $\bullet$ Romantic relationship $\bullet$ Attachment $\bullet$ Peer pressure $\bullet$ Media socialization

J. Van Ouytsel $(\bowtie) \bullet$ M. Walrave

Department of Communication Studies, MIOS, University of Antwerp, Antwerp, Belgium

K. Ponnet

Department of Communication Studies, MIOS, University of Antwerp, Antwerp, Belgium

Department of Communication Sciences, IMEC-MICT, Ghent University, Ghent, Belgium

M. Walrave et al. (eds.), Sexting, Palgrave Studies in Cyberpsychology, https://doi.org/10.1007/978-3-319-71882-8_3 